\title{
Childhood Stroke: A Cross-sectional Study in a Tertiary Level Hospital of Bangladesh
}

\author{
Farhana Rahman ', Fauzia Nahid ${ }^{2}$, Mahmuda Begum ${ }^{3}$, Nadia Nusrat ${ }^{4}$
}

\begin{abstract}
Background \& objective:The present study was undertaken to find the prevalence and pattern of childhood stroke and to see its clinical presentation and sub-types.

Materials \& Methods: The present cross sectional study was conducted in the Department of Pediatrics, BSMMU, Dhaka over a period of 6 months. A total of 30 children suffering from childhood stroke, provisionally diagnosed on the basis of clinical criteria and confirmed by neuroimaging were the study population. The demographic variables were age, sex, age at onset and age at case taking. The signs and symptoms at presentation, causes, investigations, neuro-imaging findings and final diagnosis were recorded.

Result: Over half (53.4\%) of the patients were in the range of $13-36$ months with mean age of the patients being $39.1 \pm 8.2$ months. The mean age at onset was $36.2 \pm 8.3$ months. About $47 \%$ of patients were male and $53 \%$ female. Paresis of limb was invariably present, unconsciousness at onset $(50 \%)$, convulsion $(33.3 \%)$, aphasia $(26.7 \%)$, raised blood pressure $(23.3 \%)$, vomiting $(13.3 \%)$, visual defect $(8.7 \%)$ and headache $(6.7 \%)$. Arterial occlusion was the main cause of childhood stroke $(36.7 \%)$ followed by hypertensive encephalopathy (10\%), migraine, hematoligical disease, cardiomyopathies (each 6.7\%). Investigations revealed that over one-third $(36.7 \%)$ of the patients had leucocytosis and $13.3 \%$ abnormal echocardiography. All the children either exhibited ischemia or infarction or hemorrhage on Computed Tomography (CT) and $86.7 \%$ on Magnetic Resonance Imaging (MRI). Seventy percent and $36.7 \%$ of patients had MRA and MRV abnormality respectively. About $47 \%$ of the patients had acute ischemic stroke, $13.3 \%$ AIS with left-sided haemiparesis with facial palsey and another $13.3 \%$ AIS with right-sided haemiparesia. Acute haemorragic stroke (AHS), acute stroke with $\mathrm{Hb}$ beta-thalassaemia, acute stroke with right-sided haemiparesis with cardiomyopathy and recurrent haemorragic stroke were rare.

Conclusion: The study concluded that childhood stroke occurs most frequently between one to three years of age and equally affects male and female. Paresis of limb and unconsciousness at the onset were the main presenting features and arterial hypertension and hypertensive encephalopathy were the common cause of childhood stroke. Nearly three-quarters of the children present with ischemic stroke and the rest with haemorrhagic stroke.
\end{abstract}

Key words: Pattern, presentation and sub-types of childhood stroke etc.

\section{INTRODUCTION}

Childhood stroke is emerging as a serious and frequent disorder. ${ }^{1}$ It is one of the top ten causes of childhood death with high risk of serious morbidity for the survivors in the developed countries. $^{2}$ A retro-prospective (retrospective from 2003-1995 and a prospective study from 2004-2006) of childhood stroke (arterial ischemic, hemorrhagic, and sinovenous thrombosis) and transient ischemic attack conducted in Estonia demonstrated an incidence of childhood stroke to be $2.73 / 100,000$ person-years for children aged

\footnotetext{
Authors' information:

${ }^{1}$ Dr. Farhana Rahman, Assistant Professor (Pediatrics), Delta Medical College, Dhaka.

${ }^{2}$ Dr. Fauzia Nahid, Assistant Professor (Pediatrics), Dhaka Central International Medical College \& Hospital (DCIMCH), Dhaka.

${ }^{3}$ Dr. Mahmuda Begum, Junior consultant (Pediatrics), Kaliakoir Upazila Health Complex, Gazipur

${ }^{4}$ Dr. Nadia Nusrat, Assistant Professor (Pediatrics), Delta Medical College, Dhaka.
}

Correspondence: Dr Farhana Rahman, Phone:+8801990285114 E-mail:farhana013@gmail.com 
30 days to 18 years: $1.61 / 100,000$ for arterial ischemic stroke, $0.87 / 100,000$ for hemorrhagic stroke, $0.25 / 100,000$ for sinovenous thrombosis, and $0.37 / 100,000$ for transient ischemic attack. No arterial ischemic stroke patients died within 30 days, but case-fatality for intracerebral hemorrhage was $46 \%$. Focal signs occurred in $100 \%$ of arterial ischemic strokes and $64 \%$ of intracerebral hemorrhage cases. ${ }^{3}$

Research studies reported that in one-third of the cases, even in the best diagnostic centres, the causes of acute stroke remains obscured. ${ }^{4}$ However, occlusive vascular disease (ischemic stroke) comprises $55 \%$ and intracranial haemorrhage $45 \% .^{5}$ Of the ischemic strokes, congenital cyanotic heart disease may cause cerebrovascular thrombosis before 2 years of age. Acquired heart diseases that may be implicated with ischemic stroke are rheumatic heart disease, endocarditis, cardiomyopathies, arrhythmia and cardiac interventions are commonly reported. Of the vascular problems, infections, migraine, hypertensive encephalopathy and MoyaMoya diseases are more often associated with ischemic stroke. ${ }^{6}$ Haematologic and hypercoagulable states like sickle-cell anemia, polycythemia, thrombosis, leukemia and sickle cell anemia usually associated ischemic stroke. For arterial ischemic stroke, the most common underlying conditions are sickle cell disease (SCD) and congenital or acquired heart disease. The incidence of stroke in sickle cell anemia is as high as 300 per 100000 sickle-cell anemia cases below 15 years of age. Heart disease and chronic anemia (including SCD and $\beta$-thalassemia) also are risk factors for cerebral venous sinus thrombosis (CVST). Head trauma appears to be a trigger for arterial stroke and dehydration for venous stroke, whereas infections, including varicella, meningitis, tonsillitis, and otitis media, anemia, leukocytosis, and prothrombotic disorders are probably risk factors for both. It is increasingly evident that many children have multiple risk factors that together determine the risk of stroke or stroke recurrence. ${ }^{5}$ Sinovenous occlusion is suspected if focal deficit, raised intracranial pressure and seizures occur in the setting of chronic sinusitis, otitis or orbital cellulites, haemoglobinopathies, congestive heart failure etc. Etiologies of haemorrhagic stroke include arterio-venous malformations, aneurysm, arterial hypertension, arteriopathies, cerebral venous occlusive disease $\&$ intracranial tumours, trauma and cerebral and systemic infections. ${ }^{7}$

In recent years clinical, basic and populationbased studies have resulted in an increased awareness of the frequencies and features of stroke syndromes in children. Advances in neuroimaging and other laboratory testing approaches have resulted in an increased detection of stroke subtypes. A study to find the pattern of clinical presentation of childhood stroke and its subtypes will be useful in clinical decision making about its management and assessing prognosis. The present study was, therefore, undertaken to find the prevalence and pattern of childhood stroke and to see its clinical presentation sub-types.

\section{MATERIALS \& METHODS:}

This cross-sectional study was conducted in the Department of Pediatrics, Bangabandhu Sheikh Mujib Medical University (BSMMU), Dhaka Bangladesh over a period of 6 months. Children suffering from stroke, provisionally diagnosed on the basis of clinical criteria and confirmed by neuroimaging were the study population. All children of stroke irrespective of sexes were included in the study. However, parents of children refusing to give consent were excluded. A total of 30 children were consecutively included in the study. Prior permission was taken for this study from the Institutional Review Board (IRB) of BSMMU, Dhaka and informed consent was taken from the parents to allow their children to participate in the study.

Data were collected using a structured questionnaire (research instrument) containing all the variables of interest. The demographic variables were age, sex, age at onset and age at case taking. The signs and symptoms at presentation, causes, investigations, neuroimaging findings and final diagnosis were recorded. Data were collected by interview of the children's 
parents, clinical examination and laboratory investigations of the children and were processed and analysed using software SPSS (Statistical Package for Social Sciences) version 11.5. The test statistics used to analyse the data were descriptive statistics.

\section{RESULTS:}

Over half $(53.4 \%)$ of the patients were in the range of $13-36$ months with mean age of the patients being $39.1 \pm 8.2$ months. The mean age at onset was $36.2 \pm 8.3$ years. About $47 \%$ of patients were male and $53 \%$ female (Table I). All of the patients exhibited paresis of limb, followed by unconsciousness at onset $(50 \%)$, convulsion $(33.3 \%)$, aphasia $(26.7 \%)$, raised blood pressure $(23.3 \%)$, vomiting $(13.3 \%)$, visual defect $(8.7 \%)$ and headache $(6.7 \%)$ (Table II). Arterial occlusion was the main cause of childhood stroke $(36.7 \%)$ followed by migraine $(6.7 \%)$, hematological disease $(6.7 \%)$, hypertensive encephalopathy $(10 \%)$, cardiomyopathies $(6.7 \%)$, other cardiac disease $(6.7 \%)$, arterial hypertension $(10 \%)$ and others $(13.3 \%)$ (Table III).

Investigation findings show that over one-third $(36.7 \%)$ of the patients had leucocytosis and 13.3\% abnormal echocardiography. Raised ESR, thrombocytosis, thrombocytopenia, microbocytopenia, protein $\mathrm{C}$ deficiency, protein $\mathrm{S}$ deficiency, raised TSH and abnormal $\mathrm{X}$-ray chest were present in very few patients (each 6.7\%) (Table IV). All the children exhibited ischemia or infarction or hemorrhage on Computed Tomography (CT) and $86.7 \%$ on Magnetic Resonance Imaging (MRI). Seventy percent and $36.7 \%$ of patients had MRA and MRV abnormality respectively (Table V). About $47 \%$ of the patients were diagnosed as having acute ischemic stroke (AIS), 13.3\% AIS with left-sided haemiparesis with facial palsey and another $13.3 \%$ AIS with right-sided haemiparesis. Acute haemorragic stroke (AHS), acute stroke with $\mathrm{Hb}$ beta- thalassaemia, acute stroke with right-sided haemiparesis with cardiomyopathy and recurrent haemorragic stroke each comprised $6.7 \%$ of the cases (Table VI).
TABLE I: Distribution of patients by demographic characteristics $(\mathbf{n}=\mathbf{3 0})$

$\begin{array}{lcc}\begin{array}{l}\text { Demographic characteristics } \\ \text { Age (months) }\end{array} & \text { Frequency } & \text { Mean } \pm \text { SD } \\ <6 & 2(6.7) & 39.1 \pm 8.2 \\ 7-12 & 4(13.3) & \\ 13-36 & 16(53.4) & \\ 37-60 & 4(13.3) & \\ >60 & 4(13.3) & \\ \text { Age at onset (months) } & ---- & 36.2 \pm 8.3 \\ \text { Sex } & & \\ \text { Male } & 14(46.7) & ---- \\ \text { Female } & 16(53.3) & ----\end{array}$

TABLE II: Distribution of patients by signs \& symptoms $(n=30)$

$\begin{array}{lcc}\text { Signs \& symptoms } & \text { Frequency } & \text { Percentage } \\ \text { Paresis of limb } & 30 & 100.0 \\ \text { Unconscious at onset } & 15 & 50.0 \\ \text { Convulsion } & 10 & 33.3 \\ \text { Aphasia } & 08 & 26.7 \\ \text { Blood pressure (raised) } & 07 & 23.3 \\ \text { Vomiting } & 04 & 13.3 \\ \text { Visual defect } & 02 & 8.7 \\ \text { Headache } & 02 & 6.7\end{array}$

TABLE III: Distribution of patients by causes $(\mathbf{n}=\mathbf{3 0})$

$\begin{array}{lcc}\text { Causes } & \text { Frequency } & \text { Percentage } \\ \text { Migraine } & 02 & 6.7 \\ \text { Hematoligical disease } & 02 & 6.7 \\ \text { Hypertensive encephalopathy } & 03 & 10.0 \\ \text { Cardiomyopathies } & 02 & 6.7 \\ \text { Other cardiac disease } & 02 & 6.7 \\ \text { Arterial hypertension } & 03 & 10.0 \\ \text { Arterial occlusion/narrowing } & 11 & 36.7 \\ \text { Others } & 04 & 13.3\end{array}$

TABLE IV: Distribution of patients by investigations $(n=30)$

$\begin{array}{lcc}\text { Investigations } & \text { Frequency } & \text { Percentage } \\ \text { ESR raised } & 02 & 6.7 \\ \text { Leucocytosis } & 11 & 36.7 \\ \text { Thrombocytosis } & 02 & 6.7 \\ \text { Thrombocytopenia } & 02 & 6.7 \\ \text { Microbocytopenia } & 02 & 6.7 \\ \text { Protein C deficiency } & 02 & 6.7 \\ \text { Protein S deficiency } & 02 & 6.7 \\ \text { Raised TSH } & 02 & 6.7 \\ \text { Abnormal X-ray chest } & 02 & 6.7 \\ \text { Abnormal echocardiography } & 04 & 13.3\end{array}$




\begin{tabular}{|lcc|}
\hline \multicolumn{3}{|c|}{ TABLE V: Distribution of patients by neuro-imaging findings $(\mathbf{n}=\mathbf{3 0})$} \\
\hline Neuro imaging findings & Frequency & Percentage \\
\hline CT - Ischemia/Infarction/Hemorrhage & 30 & 100.0 \\
MRI-Ischemia/Infarction/Hemorrhage & 26 & 86.7 \\
MRA abnormality & 21 & 70.0 \\
MRS abnormality & 11 & 36.7 \\
\hline
\end{tabular}

TABLE VI: Distribution of patients by final diagnosis/Site of lesion $(n=30)$

\begin{tabular}{|c|c|c|}
\hline Final diagnosis/Site of lesion & Frequency & Percentage \\
\hline Acute ischemic stroke (AIS) & 14 & 46.7 \\
\hline $\begin{array}{l}\text { AIS with left sided haemiparesis } \\
\text { with facial palsey }\end{array}$ & 04 & 13.3 \\
\hline AIS with right-sided haemiparesis & 04 & 13.3 \\
\hline Acute haemorragic stroke (AHS) & 02 & 6.7 \\
\hline $\begin{array}{l}\text { Acute stroke with right-sided } \\
\text { haemiparesis with cardiomyopathy }\end{array}$ & 02 & 6.7 \\
\hline $\begin{array}{l}\text { Acute stroke with } \mathrm{Hb} \text { beta } \\
\text { thalassaemia }\end{array}$ & 02 & 6.7 \\
\hline Recurrent haemorrhagic stroke & 02 & 6.7 \\
\hline
\end{tabular}

\section{DISCUSSION:}

Stroke has been increasingly recognized in children in recent years, but diagnosis and management can be difficult because of the diversity of underlying risk factors and the absence of a uniform diagnostic approach. Children and adolescents with stroke have remarkable differences in presentation compared with older patients. Stroke type also varies according to age. Keeping this information in mind, this cross-sectional study was conducted to focus on the prevalence and pattern of childhood stroke attended in a tertiary hospital.

In our study, mean age of the patients at presentation and at onset were 39.1 and 36.2 months respectively. Male female ratio was roughly $1: 1$. Paresis of limb was invariably present, followed by unconscious (50\%), convulsion $(33 \%)$, aphasia $(26.7 \%)$, raised blood pressure $(23.3 \%)$, vomiting $(13.3 \%)$, visual defect $(8.7 \%)$ and headache $(6.7 \%)$. Arterial occlusion and narrowing was the main cause of childhood stroke (36.7\%). Second leading causes were hypertensive encephalopathy (10\%) and arterial hypertension (10\%). The least common causes were migraine $(6.7 \%)$, hematological disease $(6.7 \%)$, cardiomyopathies $(6.7 \%)$, other cardiac and other diseases (20\%). On Computed Tomography (CT) of brain all the children either exhibited ischemia or infarction or hemorrhage, while on Magnetic Resonance Imaging (MRI), $86.7 \%$ were diagnosed as having ischemia or infarction or hemorrhage. Seventy percent and $36.7 \%$ of patients had MRA and MRV abnormality respectively. About $47 \%$ of the patients were diagnosed as having AIS, $13.3 \%$ AIS with left-sided haemiparesis with facial palsey and another $13.3 \%$ AIS with right-sided haemiparesis. Acute haemorragic stroke (AHS), acute stroke with $\mathrm{Hb}$ beta-thalassaemia, acute stroke with right-sided haemiparesis with cardiomyopathy and recurrent haemorragic stroke were rare. Thus, it is evident from the data that over $70 \%$ of the stroke in children are ischemic and the rest are haemorrhagic which is quite consistent with Ganesanet al. ${ }^{5}$ study. In children, $55 \%$ of strokes are ischemic, and the remainder is hemorrhagic Hemiplegia, headache, seizure or altered levels of consciousness may all herald a potentially reversible or lethal medical or surgical stroke emergency. In addition to the underlying diagnosis, the time from onset of symptoms to presentation is very useful diagnostically, for example arterial occlusion or narrowing is more likely to present with a stuttering onset, ${ }^{8}$ suggesting the need for imaging to exclude dissection, while "thunderclap" headaches may be indicative of a subarachnoid haemorrhage warranting lumbar puncture even if neuroimaging is normal. Stroke may be benign and require no treatment, but in some cases timely intervention prevents neurological disability or death. Emergency MRI provides information that can guide management in individual children.9,10

Lynch \& $\operatorname{Han}^{11}$ in an attempt to focus on the mechanism of stroke established the pathophysiologic process in $78 \%$ of the children with stroke. Arteriopathic stroke (31 patients, or $53 \%$ ) was the most common. The arteriopathies 
were either progressive (Moya in 7\% patients) or non-progressive ( $46 \%$ patients). The latter form occurred in two patterns: dissection of cervicocephalic arteries (20\%) and transient cerebral arteriopathy of unknown origin but probably angiitis (25\%). Cardiac or transcardiac embolic stroke occurred in $12 \%$ of the series and systemic diseases in $14 \%$. There was a favorable outcome in $70 \%$ of patients having stroke due to nonprogressive arterial disease and stroke due to unidentified mechanisms. In contrast, only $26 \%$ of patients with embolic stroke, systemic disease, or MoyaMoya had a favorable outcome. Recurrences were more frequent and severe in the latter group. It is therefore, important to determine the mechanism of childhood stroke, because it strongly influences outcome, the recurrence risk, and treatment choice.

Furthermore, deVeber ${ }^{12}$ reported almost $58 \%$ of their older subjects were in patients at the time of their AIS, and almost $69 \%$ had known cardiac risk factors for stroke. This is important because cardiac disease is the most common, previously recognized risk factor. Gabiset al. ${ }^{13}$ demonstrated a large prehospital delay (mean time: 28.5 hours) contributing to the overall delay in stroke diagnosis (mean time: 35.7 hours). One half of the physicians documented a differential diagnosis, and even fewer included stroke in the list of possibilities. In another study, McGlennan \& Ganesan $^{14}$ demonstrated cranial ultrasonography and CT scanning are not as sensitive as MRI of the brain when used as the initial imaging modality to diagnose AIS.

\section{CONCLUSION:}

The study concluded that childhood stroke occurs most frequently between one to three years of age and equally affects male and female. Paresis of limb and unconsciousness at the onset were the predominant clinical features and arterial hypertension and hypertensive encephalopathy were the common cause of childhood stroke. Nearly three-quarters of the children present with ischemic stroke and the rest with haemorrhagic stroke.

\section{REFERENCES:}

1. De Veber \& Gabrielle. Stroke and the child's brain: an overview of epidemiology, syndromes and risk factors. Current Opinion in Neurology 2002;15(2):133-8.

2. Mallick AA \& O'Callaghan FJK. European The epidemiology of childhood stroke. Journal of Paediatric Neurology 2010;14(3):197-205.

3. Laugesaar R, Kolk A, Uustalu U, Ilves $P$, Tomberg T, Talvik I et al. Epidemiology of Childhood Stroke in Estonia. Pediatric Neurology 2010;42(2):93-100.

4. Brower MC, Rollins N \& Roach ES. Basal ganglia and thalamic infarction in children. Cause and clinical features. Arch Neurol 1996;53:1252-56.

5. Ganesan V, Prengler M, McShane MA, Wade AM \& Kirkham FJ. Investigation of risk factors in children with arterial ischemic stroke. Ann Neurol 2003;53:167-73.

6. Kurnik K, Kosch A, Sträter R, Schobess R, Heller C \& Nowak-Gottl U. Stroke Study Unit. Recurrent thromboembolism in infants and children suffering from symptomatic neonatal arterial stroke: a prospective follow-up study. Stroke 2003;34:2887-92.

7. Duhem R, Vinchon M, Leblond P, Soto-Ares G \& Dhellemmes P. Cavernous malformations after cerebral irradiation during childhood: report of nine cases. Childs Nerv Syst 2005;21:922-5.

8. Braun KP, Rafay MF, Uiterwaal CS, Pontigon A M \& De Veber G. Mode of onset predicts etiological diagnosis of arterial ischemic stroke in children. Stroke 2007;38(2): 298-302.

9. Braun KP, Kappelle LJ, Kirkham FJ, Deveber G. Diagnostic pitfalls in paediatricischaemic stroke. Dev Med Child Neurol 2006;48(12):985-90.

10. Shellhaas RA, Smith SE, O'Tool E, Licht DJ \& Ichord RN. Mimics of childhood stroke: characteristics of a prospective cohort. Pediatrics 2006;118(2):704-9.

11. Lynch JK \& Han CJ. Pediatric stroke: what do we know and what do we need to know. Semin Neurol $2005 ; 25: 410-23$.

12. de Veber G. Canadian Pediatric Ischemic Stroke Study Group. Canadian Pediatric Ischemic Stroke Study registry: analysis of children with arterial ischaemic stroke. Ann Neurol 2000;48(4):514.

13. Gabis LV, Yangala R \& Lenn NJ. Time lag to diagnosis of stroke in children. Pediatrics 2002;110(5):924- 8.

14. Mc Glennan \& Ganesan. Delays in investigation and management of acute arterial ischaemic stroke in children. Dev Med Child Neurol 2008;50(7):537-40. 